\title{
Evaluasi Program Art Therapy Bagi Pasien Dual Diagnosis (NAPZA-Skizofrenia) di Rumah Sakit Ketergantungan Obat (RSKO) Jakarta
}

\author{
Nurbani Ulfah
}

\begin{abstract}
Abstrak
The main problem drug users with psychiatric disorders is the difficulty of communicating the reason they use drugs and express their feelings on the condition of the Counselor or Social Worker (Therapist). The existence of the program of art therapy for patients with drug with psychiatric disorders (dual diagnosis) is part of psychotherapy as an adjunct therapy in the form of art to channel emotions, express their feelings when communicate verbally is difficult, and to express themselves freely in order to improve their condition in the direction better in recovering. In an effort to redress for victims of drug abuse, especially for people with dual diagnosis due to drug addiction, the Drug Dependency Hospital (RSKO) is a reference center for rehabilitation using the Therapeutic Community (TC) based hospitals that have programs therapies to restore health and capabilities in the field of art, one through the art therapy program.
\end{abstract}

Key Words: Evaluasi Program, Art Therapy, Dual Diagnosis (NAPZA-Skizofrenia), dan Pekerja Sosial Medis/Klinis.

\section{Pendahuluan}

Narkotika, Psikotropika, dan Zat Adiktif lainnya (NAPZA) adalah bahan atau zat yang bila masuk ke dalam tubuh akan mempengaruhi tubuh terutama susunan syaraf pusat/otak sehingga bilamana disalahgunakan akan menyebabkan Gangguan fisik, psikis/jiwa, dan fungsi sosial. Susunan syaraf pusat atau fungsi otak merupakan bagian yang paling penting di dalam tubuh setiap manusia. Oleh karena itu, kerja tubuh manusia diatur sebaik mungkin menggunakan otak. Penyalahgunaan NAPZA menimbulkan dampak antara lain merusak hubungan kekeluargaan, menurunkan kemampuan belajar, ketidakmampuan untuk membedakan mana yang baik dan mana yang buruk. Mana yang halal dan yang haram, perubahan mental dan perilaku menjadi anti-sosial (psikopat), merosotnya produktivitas kerja, gangguan kesehatan, mempertinggi kecelakaan lalu lintas, kriminalitas, dan tindak kekerasan lainnya, serta berakhir pada kematian yang sia-sia (Hawari, 2004: III)

Agama Islam telah mengatur dengan baik tujuan hidup manusia sebagai anggota masyarakat, yakni terbentuknya kehidupan masyarakat yang sejahtera dan damai. Terdapat beberapa ayat al-Quran dan Hadits yang melarang manusia untuk mengkonsumsi minuman keras dan hal-hal yang memabukkan termasuk narkoba. Pada zaman Rasulullah SAW, zat berbahaya yang paling populer memang baru minuman keras (khamar). Seiring perkembangan dunia Islam, khamar kemudian bermetamorfosa dalam bentuk yang canggih atau yang lazim disebut narkotika/narkoba. Untuk itu, larangan mengkonsumsi minuman keras dan halhal yang memabukkan adalah sama dengan larangan mengkonsumsi narkoba. Sebagaimana yang dijelaskan dalam Sûrah al-Maidah/5 ayat 90 dan 91 . Artinya:

"Hai orang-orang yang beriman, sesungguhnya (meminum) khamar, berjudi, (berkorban untuk) berhala, mengundi nasib dengan panah, adalah termasuk perbuatan syaitan. Maka jauhilah perbuatan-perbuatan itu agar kamu mendapat keberuntungan."

"Sesungguhnya syaitan itu bermaksud hendak menimbulkan permusuhan dan kebencian diantara kamu lantaran (meminum) khamar dan berjudi itu, dan menghalangi kamu dari mengingat Allah dan sembahyang; maka berhentilah kamu (dari mengerjakan pekerjaan itu)." (Al.Quran) 
Faktanya penyalahgunaan NAPZA saat ini telah mencapai situasi yang sangat mengkhawatirkan bagi kelangsungan hidup manusia. Berdasarkan data dari penelitian Badan Narkotika Nasional (BNN) dan Puslitkes UI prevalensi penyalahgunaan narkoba tahun 2011 meningkat sebesar 2,2 persen, sementara tahun 2013 bisa meningkat 2,56 persen dan 2015 bisa melonjak 2,80 persen. (RakyatMedia). Dampak penyalahgunaan NAPZA sebagian besar mengarah pada gangguan psikis seseorang. Departemen Kesehatan Republik Indonesia (2001) menyatakan bahwa gejala psikiatri yang timbul adalah cemas, depresi dan halusinasi. Penelitian yang dilakukan di USA menunjukkan lebih dari 50\% penyalahgunaan NAPZA non alkohol mengidap paling tidak satu gangguan psikiatri antara lain:

1) $26 \%$ mengalami gangguan alam perasaan seperti depresi (sedih, muram, tertekan), mania (kegelisahan, kemarahan, kekalutan atau kebingungan yang berlebihan).

2) $26 \%$ gangguan ansietas (kecemasan berlebihan).

3) $18 \%$ gangguan kepribadian antisosial (tidak perduli dengan hak orang lain).

4) $7 \%$ skizofrenia (gangguan otak yang rumit/kronis)

Mereka dengan penyalahgunaan alkohol sebanyak 37\% mengalami komordibitas psikiatri (gangguan psikis lain). Berdasarkan data DepKes, saat ini terdapat lebih dari 3,5 juta pecandu narkoba di Indonesia. Sebagian besar diantaranya 43\%-67\% mengalami Gangguan Diagnosis Ganda (GDG). (USUPress)

Berdasarkan Pedoman Penggolongan dan Diagnosa Gangguan Jiwa (PPDGJ), dual diagnosis, yakni sindrom klinis atau gangguan mental menyangkut kondisi lain yang menjadi fokus perhatian klinis. Gangguan klinis dalam hal ini termasuk ke dalam gangguan yang berhubungan dengan obat dan NAPZA, termasuk gangguan penggunaan alkohol, gangguan penggunaan amphetamin, gangguan yang dipicu oleh penggunaan cannabis (ganja), gangguan yang dipicu oleh anxiolitic, hipnotic, dan sedatif (obat penenang) (Maslim, 1996: 41).

Upaya penanggulangan penyalahgunaan NAPZA secara komprehensif adalah melalui pendekatan Harm Minimisation, yang secara garis besar dikelompokkan menjadi tiga kegiatan utama yaitu Supply Control, Demand Reduction, dan Harm Reduction. Termasuk upaya Supply Control adalah penegakkan hukum, pencegahan penyelundupan dan peredaran NAPZA; termasuk Demand Reduction adalah upaya di bidang prevensi, terapi dan rehabilitasi. Sehubungan dengan hal tersebut di atas maka tidak ada istilah terlambat untuk memerangi NAPZA dengan strategi Supply Control dan Demand Reduction yang dijalankan secara konsekuen, konsisten, dan berkesinambungan, hal ini mengingat bahwa sebagian besar (90\%) korbannya adalah remaja anak bangsa yang merupakan generasi penerus bangsa dan negara yang merupakan kewajiban pemerintah dan masyarakat untuk melindungi masa depannya. Upaya Demand Reduction salah satunya adalah dengan cara terapi. Terapi adalah perlakuan (treatment) yang ditujukan terhadap penyembuhan suatu kondisi psikologis individu. Pada beberapa tempat rehabilitasi menawarkan berbagai macam bentuk terapi, salah satu bentuk terapi dalam proses rehabilitasi adalah art therapy. Dalam proses kegiatan art therapy, pasien diberikan layanan dan bimbingan seni yang terdiri atas proses komunikasi non-verbal melalui garis, bentuk, dan warna; ekspresi dari ide dan perasaan (Hawari, 2004: 268).

Fenomena yang terjadi di Amerika Serikat (AS), seni lukis pasir sebagai coping digolongkan dalam strategi penyelesaian masalah termasuk dalam kategori art therapy. Menurut Michael Levin, Art therapy adalah disiplin ilmu yang kuat yang digunakan dalam pengobatan gangguan mental atau saraf dan untuk meningkatkan kualitas kehidupan. Rehabilitasi dengan art therapy sebagai wadah penyaluran kreatifitas dan pengalihan pasien kepada NAPZA untuk tidak mengkonsumsi kembali. Terkadang pasien sering mengalami 
kesulitan dalam menentukan pilihan sehingga tidak sedikit pasien yang berbakat, kemampuan minat dan hobinya tidak tersalurkan dengan baik. Pasien seperti ini tidak dapat mencapai perkembangan rehabilitasi secara optimal, mereka memerlukan bantuan atau bimbingan dari orang-orang dewasa, terutama terapis atau konselor dalam menyalurkan potensi dan mengembangkan dirinya (Prayitno, 2004: 122).

Sebagai upaya penanganan bagi korban penyalahgunaan NAPZA khususnya bagi penderita dual diagnosis yang disebabkan karena ketergantungan obat atau narkotika, salah satunya yakni mendirikan panti rehabilitasi maupun rehabilitasi berbasis rumah sakit yang memiliki program terapi-terapi untuk memulihkan kesehatan dan menyalurkan bakat kemampuan di bidang seni. Rumah Sakit Ketergantungan Obat (RSKO) merupakan rumah sakit yang menangani dan mengobati para korban penyalahgunaan NAPZA yang terletak di Jalan Lapangan Tembak Nomor. 75 Cibubur, Jakarta Timur. RSKO menggunakan program art therapy sebagai alternatif dalam merehabilitasi pasien penyalahgunaan NAPZA khususnya bagi pasien dual diagnosis.

Berdasarkan data yang penulis dapatkan dari Pekerja Sosial di RSKO, pada tanggal 20 Mei 2014 jumlah seluruh pasien rehabilitasi di RSKO sebanyak 37 orang. Dari keseluruhan jumlah pasien yang di rehabilitasi, pasien yang dual diagnosis sebanyak 15 orang. Pasien dual diagnosis yang menjalani pemulihan di RSKO berjenis kelamin laki-laki dan rata-rata usianya diatas 20 tahun. RSKO menyediakan fasilitas dan program bagi pasien dual diagnosis untuk meningkatkan kemampuan serta perubahan sikap dan mental positif. Penulis tertarik untuk mengkaji lebih dalam tentang program art therapy terkait dengan evaluasi program terhadap pemulihan pasien dual diagnosis di Rumah Sakit Ketergantungan Obat (RSKO) Jakarta. Penulis membatasi penelitian pada evaluasi program art therapy bagi pasien dual diagnosis di RSKO Jakarta. Evaluasi yang dimaksud dalam penelitian ini adalah melihat secara keseluruhan mulai dari perencanaan, proses, hingga hasil dan dampak dari pelaksanaan kegiatan program art therapy terhadap pasien dual diagnosis, yakni pasien NAPZA yang mengalami gangguan kejiwaan (Skizofrenia) di Rumah Sakit Ketergantungan Obat Jakarta.

\section{Metodologi Penelitian}

Dalam penelitian ini penulis menggunakan pendekatan metode penelitian kualitatif, yaitu suatu penelitian yang berupaya menghimpun data, mengolah dan menganalisa data secara kualitatif dan menafsirkannya secara kualitatif. Metodologi kualitatif sebagai prosedur penelitian yang menghasilkan data deskriptif berupa kata-kata tertulis atau lisan dari orang-orang dan perilaku yang dapat diamati (Moleong, 2001: 9). Penulis menggunakan pendekatan kualitatif dalam melakukan penelitian agar dapat memiliki dan menyajikan data yang akurat dari pelaksanaan program art therapy bagi pasien dual diagnosis di Rumah Sakit Ketergantungan Obat (RSKO) Jakarta. Penulis bermaksud untuk meneliti secara mendalam mengenai pelaksanaan program art therapy dan evaluasi program art therapy bagi pasien dual diagnosis (NAPZA-Skizofrenia) di Rumah Sakit Ketergantungan Obat (RSKO) Jakarta. Adapun waktu waktu pelaksanaan penelitian ini dilakukan sejak 1 April 2014 hingga 30 Mei 2014. Teknik pemilihan informan dalam penelitian ini menggunakan teknik purposive sampling yang memberikan keleluasaan kepada peneliti dalam menyeleksi informan yang sesuai dengan tujuan penelitian, yang terpenting disini bukanlah jumlah informan, melainkan potensi dari tiap kasus untuk memberikan pemahaman teoritis yang lebih baik mengenai aspek yang dipelajari. Dalam teknik pengumpulan data, penulis melakukan observasi, wawancara, dan dokumentasi. Penulis melakukan wawancara kepada tiga orang peserta, satu orang salah satu perwakilan dari keluarga pasien, dan empat orang yang mewakili manajemen Rumah Sakit Ketergantungan Obat Jakarta. 


\section{Definisi Evaluasi Program Art Therapy}

Evaluasi

Menurut Suharsimi Arikunto, evaluasi adalah kegiatan untuk mengumpulkan informasi tentang bekerjanya sesuatu, yang selanjutnya informasi tersebut digunakan untuk menentukan alternatif yang tepat dalam mengambil keputusan. Fungsi utama evaluasi dalam hal ini adalah menyediakan informasi yang berguna bagi decision maker (pembuat keputusan) untuk menentukan kebijakan yang akan diambil berdasarkan evaluasi yang telah dilakukan (Nana Minarti, 2009: 23).

Scriven membedakan antara evaluasi formatif dan evaluasi sumatif sebagai fungsi evaluasi yang utama. Fungsi evaluasi formatif, yaitu evaluasi untuk perbaikan dan pengembangan kegiatan yang sedang berjalan (program, orang, produk, dan sebagainya). Fungsi evaluasi sumatif, yaitu evaluasi dipakai untuk pertanggungjawaban, keterangan, seleksi atau lanjutan (Tayibnapis, 2008: 4).

\section{Program}

Program adalah sederetan rencana kegiatan yang akan dilaksanakan oleh seseorang atau sekelompok organisasi, lembaga, bahkan Negara. Jadi seseorang, sekelompok organisasi, lembaga bahkan negara memiliki suatu program. Suharsimi Arikunto dalam bukunya Penilaian Program Pendidikan, program adalah sederetan rencana kegiatan yang akan dilaksanakan untuk mencapai kegiatan tertentu (Arikunto, 1998). Dalam Kamus Besar Bahasa Indonesia, definisi program adalah rencana. Maksudnya, program adalah seperti pertunjukan siaran, pagelaran, dsb (Depdikbud, 1998 702).

\section{Art Therapy (Terapi Seni)}

Terapi adalah remediasi masalah kesehatan, biasanya setelah pasien didiagnosis. Orang yang melakukan terapi disebut Terapis. Dalam bidang medis, kata terapi sinonim dengan kata pengobatan. Diantara psikolog, istilah ini mungkin merujuk secara khusus untuk psikoterapi. Selain itu, terapi merupakan suatu bentuk perlakuan dan pengobatan yang ditujukan kepada penyembuhan suatu kondisi yang menyimpang (patologis) pada diri seseorang (Chaplin, 2006: 507).

Menurut Tessa Dalley: in simple term, art therapy is the use of art and other viual media in a therapeutic or treatment setting. Secara sederhana, terapi seni adalah penggunaan seni dan media visual lainnya dalam sebuah terapeutik atau pengaturan perlakuan (Dalley, 1992: 3). Menurut Judith Aron Rubin: The essence of art therapy is that is must partake of both parts of its name-it must I volve art and therapy. The goal of the art activity, therefore, must be primarily therapeutic. This might, of course, include diagnosis as well as treatment; for in order to be an effective therapist, you must understand who and what you are treating. You must know about the nature of the treatment relationship, and the mechanisms that underlie helping others to change. Esensi terapi menurut suku kata terbagi atas seni dan terapi. Tujuan dari kegiatan seni ini pada dasarnya haruslah bersifat terapeutik. Mungkin juga dan tentunya, termasuk diagnosis yang sesuai/sebaik dengan perawatannya; untuk dapat menjadi seorang terapis, anda harus mengerti siapa dan apa yang harus mendapatkan perawatan. Anda harus mengerti tentang kelainan/pembawaaan dari sebuah hubungan perawatan dan mekanisme yang menjadi dasar dalam membantu orang lain menuju suatu perubahan (Rubin, 1984).

\section{Profil Singkat Rumah Sakit Ketergantungan Obat (RSKO) Jakarta}

Rumah Sakit Ketergantungan Obat (RSKO) Jakarta didirikan pada tahun 1972, yang sebelumnya merupakan salah satu unit RSUP Fatmawati Jakarta. Rumah sakit ini merupakan satu-satunya rumah sakit 
milik pemerintah yang khusus bergerak dalam bidang penanganan gangguan yang berhubungan dengan zat. Rumah sakit ini semula bernama Drug Dependence Unit (DDU) yang diresmikan oleh Ali Sadikin selaku Gubernur DKI Jakarta pada waktu itu. Pada tahun 1974 DDU berubah nama menjadi Lembaga Ketergantungan Obat (LKO), dimana tujuan utamanya adalah penanganan ketergantungan obat yang komperhensif dan bersifat jangka panjang, meliputi bidang preventif, kuratif, dan rehabilitatif. Pada tahun 1978, status LKO ditingkatkan menjadi rumah sakit tipe C dengan nama Rumah Sakit Ketergantungan Obat (RSKO) di bawah Departemen Kesehatan RI sebagai unit pelaksana fungsional dari Ditjen Pelayanan Medik dengan dr. Erwin Widjono, Sp.KJ sebagai direktur pertama.

Sebelumnya RSKO bertempat di Fatmawati, kemudian pada tahun 1999 Pemda DKI Jakarta memberi bantuan berupa izin persetujuan prinsip pemanfaatan tanah seluas $\pm 1,5$ hektar untuk pembangunan Rumah Sakit yang bertempat di Cibubur, Jakarta Timur. Pada tanggal 15 Oktober 2002 gedung RSKO baru di Cibubur resmi digunakan dan sejak itu secara bertahap dilakukan pemindahan seluruh aktivitas Rumah Sakit dari lokasi Fatmawati ke Cibubur. Terhitung sejak tanggal 1 Februari 2007 RSKO hanya berada pada satu lokasi, yaitu di jalan Lapangan Tembak no. 75, Cibubur, Jakarta Timur. Sejak RSKO di Cibubur resmi digunakan, telah dilakukan berbagai pengembangan layanan, yaitu unit rehabilitasi berorientasi therapeutic community (TC) berbasis rumah sakit, high care unit (HCU), laboratorium klinik dan radiologi, unit layanan umum, program subtitusi rumatan, serta fasilitas pendidikan, pelatihan dan penelitian. Pengembangan program dilaksanakan secara berkala, demi memenuhi kebutuhan pasien. Saat ini, program rehabilitasi tidak lagi secara eksklusif beorientasi pada TC, melainkan bersifat kompherensif, menggabungkan berbagai macam pendekatan, mengingat kondisi pasien juga banyak mengalami perubahan. Pengembangan rencana terapi pada berbagai program yang ada bersifat individual, disesuaikan dengan kondisi pasien secara keseluruhan.

\section{Pembahasan}

\section{Pelaksanaan Program Art Therapy di RSKO Jakarta}

Rumah Sakit Ketergantungan Obat (RSKO) sejak tahun 2003 mulai membuka layanan rehabilitasi. Orientasi program rehabilitasi yang diterapkan adalah Therapeutik Community (TC) berbasis Rumah Sakit. Program ini ditujukan pada pasien dengan berbagai latar belakang kasus NAPZA yang digunakan, baik pengguna aktif maupun mereka yang berada pada masa remisi. Seluruh pasien menjalani program yang sama dan diperlakukan sama antara pasien yang satu dengan pasien lainnya. Seiring dengan berjalannya waktu terlihat bahwa beberapa pasien memiliki kondisi fisik dan mental tertentu yang kurang tepat untuk mengikuti program tersebut. Selain tetap mempertahankan program berorientasi TC, Instalasi Rehabilitasi juga mulai mengembangkan Program Khusus (PK) bagi pasien-pasien berkebutuhan khusus. Program art therapy dibentuk pada tahun 2007 oleh Pak Isrizal yang berprofesi sebagai Psikolog di RSKO namun, semenjak Pak Isrizal sudah tidak menjadi Psikolog di RSKO pelaksanaan art therapy sepenuhnya diserahkan kepada Pekerja Sosial yang ada di RSKO yaitu Pak Syarifuddin dan Pak Agus Darmawan. Program art therapy yang berada di RSKO ditujukan secara khusus bagi pasien yang berada pada fase Special Program (SP).

Istilah dual diagnosis sudah lama terdengar di bidang NAPZA. RSKO menerapkan penatalaksanaan pasien dual diagnosis seiring dengan munculnya perilaku kekerasan, gangguan mood, gangguan pola pikir, dan gejala waham pada beberapa pasien, serta tidak adanya perkembangan positif selama mengikuti program rehabilitasi berbasis Therapeutik Community (TC) pada pasien-pasien tersebut. Oleh karena itu, RSKO memodifikasi program untuk diterapkan pada pasien dual diagnosis tersebut, yang sering disebut sebagai Program Khusus (PK). Sekalipun fokus utamanya adalah untuk menangani pasien dual diagnosis, 
namun PK ini juga dapat mengakomodasi pasien dengan keterbatasan fisik akibat komplikasi fisik yang dialaminya, pasien dengan keterbatasan kemampuan kognitif, serta pasien lain dengan kebutuhan khusus. Menurut beberapa ahli, art therapy merupakan salah satu saluran karena pasien dual diagnosis kaya akan fantasi yang luar biasa. Sehingga, art therapy dapat mewadahi. Dengan kata lain, seni dapat dijadikan sebagai kegiatan untuk mengekspresikan diri atau menceritakan pengalaman pasien. Art therapy mengubah keadaan seseorang dari kurang baik menjadi lebih baik karena pasien dapat mencurahkan isi hatinya sehingga menjadi alternatif penyembuhan diri. Prinsip dan strategi perawatan dalam PK melibatkan kerjasama dari para profesional dan petugas lain, yaitu: Dokter Umum, Psikiater, Neurolog, Dokter Penyakit Dalam, Psikolog, Perawat, Pekerja Sosial, Konselor Adiksi dan Ahli Gizi.

Jenis kegiatan yang diterapkan dalam pelaksanaan art therapy di RSKO sebagai berikut:

Tabel 4

Jadwal Kegiatan Art Therapy

\begin{tabular}{|c|c|c|c|c|c|}
\hline No. & $\begin{array}{c}\text { Minggu } \\
\mathrm{Ke} \mathrm{I}\end{array}$ & $\begin{array}{c}\text { Minggu } \\
\text { Ke II }\end{array}$ & $\begin{array}{c}\text { Minggu } \\
\text { Ke III }\end{array}$ & $\begin{array}{l}\text { Minggu } \\
\text { Ke IV }\end{array}$ & $\begin{array}{c}\text { Minggu } \\
\mathrm{Ke} \mathrm{V}\end{array}$ \\
\hline 1. & $\begin{array}{l}\text { Membuat foto } \\
\text { dengan per- } \\
\text { antara kertas } \\
\text { yang dibolongi } \\
\text { persegi empat. }\end{array}$ & $\begin{array}{l}\text { Membuat puisi } \\
\text { dan memba- } \\
\text { cakannya. } \\
\text { Permainan } \\
\text { musik bumi. }\end{array}$ & $\begin{array}{l}\text { Lomba baca } \\
\text { puisi dan } \\
\text { menceritakan } \\
\text { makna yang } \\
\text { terkandung. }\end{array}$ & $\begin{array}{l}\text { Menggambar } \\
\text { berdua den- } \\
\text { gan menarik } \\
\text { garis atau titik } \\
\text { awal. }\end{array}$ & $\begin{array}{l}\text { Menggambar } \\
\text { diri orang } \\
\text { lain. } \\
\text { Mengolah } \\
\text { vokal dan } \\
\text { praktek } \\
\text { membaca } \\
\text { cepat. }\end{array}$ \\
\hline No. & Minggu VI & Minggu VII & Minggu VIII & Minggu IX & Minggu $\mathrm{X}$ \\
\hline 2. & $\begin{array}{l}\text { Observasi dan } \\
\text { menyatukan } \\
\text { gambar yang } \\
\text { terpisah-pisah. }\end{array}$ & $\begin{array}{l}\text { Tentang nama } \\
\text { yang dibalik } \\
\text { dan sejarah } \\
\text { nama. }\end{array}$ & $\begin{array}{l}\text { Menulis tujuan } \\
\text { hidup, mengo- } \\
\text { lah vokal dan } \\
\text { permainan. }\end{array}$ & $\begin{array}{l}\text { Menggambar } \\
\text { teman dan } \\
\text { permainan } \\
\text { botol. }\end{array}$ & $\begin{array}{l}\text { Membuat } \\
\text { puisi per- } \\
\text { juangan. }\end{array}$ \\
\hline
\end{tabular}

Kegiatan atau materi-materi yang sudah tertera di jadwal tidak tetap. Artinya sewaktu-waktu jadwal tersebut dapat berubah atau dapat digantikan dengan materi yang lain atau terapi yang lain.

Dari data di atas dapat saya simpulkan bahwa peserta (pasien) dapat menjalani kegiatan art therapy disesuaikan dengan keadaan dan kegiatan pasien yang lain selama menjalani rehabilitasi atau pemulihan di RSKO. Sehingga Pekerja Sosial dituntut untuk selalu inovatif dalam menciptakan kegiatan yang baru agar tidak monoton di setiap kegiatan art therapy. Terkadang kegiatan art therapy tidak dapat dilakukan sesuai jadwal karena ketidakhadiran Pekerja Sosial yang sedang mengikuti seminar/pelatihan di luar RSKO ataupun para pasien yang sedang mendapatkan kegiatan lain dari program rehabilitasi (Therapeutic Community). Dengan demikian dalam memberikan pelayanan kepada klien atau pasien dual diagnosis, Pekerja Sosial harus memahami peran dan fungsinya, serta memahami dinamika pasien dual diagnosis.

Berikut gambaran kasus dari tiga orang klien atau pasien dual diagnosis (NAPZA-Skizofrenia) yang sedang menjalani rehabilitasi di RSKO Jakarta: 


\section{a. Kasus 1}

Klien "T" putra dari Bapak "YLT" dan Ibu “T”. Klien berusia 32 tahun. Klien berasal dari Batam. Pendidikan terakhir klien SMP. Agama yang dianut klien yaitu Budha. Klien tidak bekerja dan sedang menjalani pemulihan di RSKO Jakarta. Klien sudah menjalani pemulihan di RSKO Jakarta selama enam bulan. Klien " $T$ ” menggunakan NAPZA jenis psikotropika yaitu methamphetamine. Selain itu, klien "T" juga menggunakan NAPZA jenis narkotika yaitu shabu. Klien " $T$ " mengalami gelisah, sulit tidur, dan klien " $\mathrm{T}$ " mengalami gangguan mental akibat zat stimulan. Klien " $\mathrm{T}$ " mendapat diagnosa dual diagnosis (NAPZA-Skizofrenia). Kondisi fisik klien "T" juga mengalami sakit, yaitu klien menderita Hepatitis B. Klien "T" sudah memiliki satu orang anak, namun ia mengalami perceraian. Keadaan ekonomi keluarga klien "T" berkecukupan. Klien "T” dibawa ke RSKO oleh kakak kandungnya dengan cara dibohongi dengan alasan mengajak klien "T" untuk jalan-jalan.

Berdasarkan hasil pemeriksaan Dokter pada bulan Mei 2014, klien "T" sudah tenang, relaks, dan sudah mulai bisa tidur. Resep yang diberikan oleh Dokter juga diminum secara rutin. Obat yang Dokter berikan kepada klien "T" yaitu THP dan clozaril. Dari data di atas dapat saya simpulkan bahwa, terdapat beberapa tujuan art therapy di RSKO yang sudah tercapai pada perubahan diri klien "T" antara lain: klien "T" merasa terhibur atau senang dengan adanya kegiatan art therapy, klien "T" menjadi relaks, dan motivasi di dalam diri klien "T" meningkat. Dengan demikian, program art therapy di RSKO berpengaruh terhadap proses pemulihan dan membawa perubahan bagi klien "T" ke arah yang positif, walaupun tidak semua tujuan program art therapy di RSKO dapat dicapai.

b. Kasus 2

Klien "IW" putra dari Bapak "SK" dan Ibu "SH". Klien berusia 34 tahun. Klien berasal dari Jakarta. Pendidikan terakhir klien SMA. Klien menganut agama Islam. Klien tidak bekerja dan sedang menjalani pemulihan di RSKO Jakarta. Klien sudah menjalani pemulihan di RSKO Jakarta selama tiga bulan. Klien "IW" menggunakan NAPZA jenis narkotika yaitu shabu dan putaw (opiat). Selain itu, klien "IW" juga menggunakan NAPZA jenis psikotropika yaitu amphetamine. Klien "IW" mengalami halusinasi dengan melihat bayangan-bayangan dan mendengar suara-suara aneh, sulit tidur, emosi tinggi, dan curiga berlebihan. Klien "IW" mendapat diagnosa dual diagnosis (NAPZA-Skizofrenia). Kondisi fisik klien "IW" juga mengalami sakit, yaitu klien menderita Hepatitis C. Status pernikahan klien "IW" mengalami perceraian dan telah memiliki satu orang anak. Latar belakang ekonomi keluarga klien berasal dari keluarga golongan menengah keatas. Berdasarkan hasil pemeriksaan Dokter pada bulan Mei 2014, klien "IW" sudah tidak ada halusinasi, sudah dapat tidur di malam hari, emosi menurun, mulai kooperatif dalam berkomunikasi, dan sudah dapat menerima kondisinya. Klien "IW" rutin meminum obat yang diberikan oleh Dokter.

Dari data di atas dapat saya simpulkan bahwa, terdapat beberapa tujuan art therapy di RSKO yang sudah tercapai pada perubahan diri klien "IW" antara lain: klien "IW" nyaman dengan adanya kegiatan art therapy dan merasa senang dapat tertawa lepas, klien "IW" menjadi relaks, menjadi lebih bijak, sudah tidak mengalami halusinasi, motivasi diri klien "IW" dalam menjalani pemulihan meningkat, dan klien "IW" dinyatakan naik fase ke Re-entry oleh Konselor pada bulan Mei. Di bulan Juli, klien "IW" mengikuti On Job Training (OJT) yaitu training khusus untuk menjadi konselor di RSKO. Dengan demikian, program art therapy di RSKO berpengaruh terhadap proses pemulihan dan membawa perubahan bagi klien "IW" ke arah yang positif, walaupun tidak semua tujuan program art therapy di RSKO dapat dicapai dan bukan semata-mata karena program art therapy tetapi gabungan dari pengobatan yang RSKO berikan kepada para pasien. 


\section{c. Kasus 3}

Klien “AHG” putra dari Bapak "ESS" dan Ibu "ES”. Klien berusia 38 tahun. Klien berasal dari Jakarta. Pendidikan terakhir klien SMA. Klien menganut agama Islam. Klien tidak bekerja dan sedang menjalani pemulihan di RSKO Jakarta. Klien sudah menjalani pemulihan di RSKO Jakarta selama tiga bulan. Klien "AHG” menggunakan NAPZA jenis narkotika yaitu shabu, ganja, dan rohipnol. Klien "AHG" mengalami halusinasi, perubahan sensorik, dan gelisah. Klien "AHG” mendapat diagnosa dual diagnosis (NAPZA-Skirzofrenia). Kondisi fisik klien “AHG” juga mengalami sakit, yaitu klien menderita Hepatitis C. Klien "AHG" memiliki satu orang anak, namun status pernikahannya sudah bercerai. Klien "AHG” berasal dari kalangan ekonomi yang berkecukupan.

Berdasarkan hasil pemeriksaan Dokter pada bulan Mei 2014, klien "AHG" sudah tidak ada halusinasi, mulai tenang, dan komunikasinya baik. Klien "AHG” rutin meminum obat yang diberikan oleh Dokter. Dari data di atas dapat saya simpulkan bahwa, terdapat beberapa tujuan art therapy di RSKO yang sudah tercapai pada perubahan diri klien "AHG" antara lain: klien "AHG” merasa terhibur atau senang dengan adanya kegiatan art therapy, klien "AHG" menjadi relaks, fungsi kognitif meningkat, dan motivasi di dalam diri klien "AHG” meningkat. Dengan demikian, program art therapy di RSKO berpengaruh terhadap proses pemulihan dan membawa perubahan bagi klien "AHG" ke arah yang positif, walaupun tidak semua tujuan program art therapy di RSKO dapat dicapai.

Berdasarkan ketiga kasus di atas, tidak terdapat perbedaan dalam proses penanganan atau pemulihan pasien. Selain itu, pasien memiliki diagnosa yang sama yaitu ketergantungan NAPZA dan gangguan kejiwaan (Skizofrenia) sehingga tidak terlihat perbandingan ataupun perbedaan yang signifikan antara pasien satu dengan yang lainnya.

\section{Analisis Hasil Evaluasi Program}

Evaluasi Input (Input)

Dalam evaluasi input memfokuskan berbagai unsur yang masuk dalam pelaksanaan suatu program. Tiga unsur (variabel) utama yang terkait dengan evaluasi input adalah klien, staf, dan program.

1. Klien

Klien atau pasien yang menjadi peserta dalam kegiatan art therapy merupakan pasien SP yang sedang menjalani rehabilitasi di RSKO. Pasien tersebut merupakan pasien dual diagnosis atau memiliki diagnosa ganda yaitu ketergantungan NAPZA dan gangguan kejiwaan. Pasien dual diagnosis memiliki keterbatasan dalam melakukan aktivitas. Mereka lebih suka menutup diri dan sulit diajak berkomunikasi. Maka dari itu, pasien dual diagnosis yang mengikuti kegiatan hanya yang dapat diajak berkomunikasi dan memahami instruksi yang diberikan Terapis/Pekerja Sosial. Kriteria pasien/klien yang dapat mengikuti kegiatan art therapy telah dijelaskankan oleh Bapak Agus Darmawan selaku Pekerja Sosial di RSKO berikut ini:

“...secara fisik terlihat sehat, pasien dapat diajak berkomunikasi walaupun yang tidak dapat diajak berkomunikasi juga diperbolehkan mengikuti program art therapy, dan pasien dapat mengikuti intruksi atau arahan dari terapis/instruktur."

2. Staff

Staff atau Terapis yang menjadi pelaksana program art therapy adalah Pekerja Sosial RSKO. Jumlah Terapis yang melaksanakan program art therapy di RSKO ada 2 (dua) orang dan memiliki latar belakang pendidikan di Perguruan Tinggi yaitu Strata 1 (S1) Sarjana Kes- 
ejahteraan Sosial. Sejak program art therapy dibentuk di RSKO, para Terapis belum pernah mengikuti pelatihan apapun yang berkaitan dengan art therapy. Pernyataan seperti itu dipaparkan oleh Pekerja Sosial RSKO, Bapak Syarifuddin berikut ini: "Saya dan rekan sebagai Terapis belum pernah mengikuti pelatihan terkait dengan kegiatan art therapy." (Wawancara Pribadi dengan Bapak Syarifuddin, tanggal 22 April 2014). Selain itu, para Terapis juga belum pernah memiliki pengalaman dalam melaksanakan kegiatan art therapy di lembaga manapun. Pekerja Sosial RSKO, Bapak Agus Darmawan juga memaparkan: "Saya dan Pak Syarif belum pernah memiliki pengalaman dalam kegiatan art therapy di lembaga lain atau di tempat lain. " (Wawancara Pribadi dengan Bapak Agus Darmawan, tanggal 22 April 2014). Sehingga dalam pelaksanaan program art therapy, para Terapis selalu berusaha untuk mengembangkan kegiatan atau materi yang akan diberikan kepada pasien dual diagnosis.

3. Program

Dalam kaitan dengan evaluasi input program, ada beberapa hal yang akan dijelaskan mengenai tujuan, standar pemberian program art therapy, dan biaya layanan program terhadap pasien dual diagnosis sebagai berikut:

a. Tujuan Program art therapy

Adapun tujuan dilaksanakannya art therapy (terapi seni) untuk membantu seseorang dengan beberapa masalah, adalah sebagai berikut: (Collingwood)

1. Memulihkan trauma masa kanak-kanak atau keluarga yang melibatkan fisik, mental, dan seksual.

2. Mengembalikan motivasi diri seseorang atau meningkatkan percaya diri.

3. Menghilangkan rasa ketakutan yang parah atau fobia.

4. Meningkatkan kemampuan kognitif.

5. Membantu menghadapi tantangan penyakit serius.

6. Memberikan treatment atau terapi bagi gangguan mental seperti skizofrenia atau depresi.

7. Membantu memahami dan berurusan dengan cacat fisik.

8. Memahami dan mengobati masalah perilaku.

Sedangkan berikut ini adalah tujuan dari art therapy yang dipaparkan oleh Pekerja Sosial RSKO, Bapak Syarifuddin:

"Tujuan art therapy secara umum agar pasien tidak merasa bosan atau jenuh, membantu proses berpikir atau kognitif pasien, melatih motorik pasien, memberikan kesempatan kepada pasien untuk mengungkapkan masalah didalam dirinya (inner problem), pasien dapat memproyeksikan dirinya ke dalam seni, mempelajari perasaan dan emosi pasien dalam membaca suatu puisi, meningkatkan pemahaman dan rasa percaya diri dan pemahaman akan lingkungan, memberikan simulasi peran dalam drama supaya pasien dapat menerapkan perannya ke dalam lingkungan masyarakat (pasien dapat bersosialisasi dengan baik), dan juga dapat meningkatkan kreatifitas pasien."

Sehingga dapat saya simpulkan bahwa peserta adalah pasien dual diagnosis atau pasien Special Programme yang sedang menjalani Rehabilitasi di RSKO. Art therapy sebagai sebuah tugas yang diprogramkan oleh Instalasi Rehabilitasi dan sebagai terapi penunjang bagi pemulihan pasien tersebut termasuk untuk mengisi waktu luang pasien. Selain itu, tujuan 
dari program art therapy lebih ke arah peningkatan atau progress didalam diri pasien seperti, cara berpikir (kognitif), motivasi dalam diri pasien, kemampuan motorik pasien, dan lain sebagainya. Dari segi indikator ketersediaan tujuan, program art therapy di RSKO Jakarta memiliki tujuan yang jelas. Selain itu, terdapat beberapa tujuan art therapy yang dikemukakan oleh para ahli sama dengan tujuan art therapy yang ada di RSKO.

b. Standar pemberian program art therapy

RSKO belum memiliki Standard Operating Procedure (SOP) art therapy. Namun, RSKO memiliki standar pemberian program art therapy yang baik. Seperti yang dipaparkan oleh Pekerja Sosial RSKO, Bapak Syarifuddin berikut ini:

"Standar pemberian program yang baik antara lain: kegiatan disesuaikan dengan kemampuan pasien, pasien merasa nyaman dan senang setelah mengikuti kegiatan, dan terpenuhinya fasilitas pasien dalam melaksanakan kegiatan."

Sehingga dapat saya simpulkan bahwa RSKO hanya memiliki standar pemberian program art therapy yang baik bagi pasien dual diagnosis. RSKO menjadikan standar pemberian program art therapy sebagai pedoman dan acuan bagi Pekerja Sosial/Terapis dalam melaksanakan kegiatan art therapy bagi pasien dual diagnosis. Standar pemberian program art therapy di RSKO lebih memperhatikan kenyamanan pasien dan disesuaikan dengan kondisi pasien.

c. Biaya layanan program art therapy

Program art therapy tergabung ke dalam Therapeutic Community (TC) sebagai terapi penunjang bagi pemulihan pasien dual diagnosis. Program art therapy di RSKO tidak diberikan secara gratis, tetapi pihak keluarga pasien yang bertanggung jawab untuk membayar setiap kegiatan atau terapi yang pasien dual diagnosis ikuti. Biaya yang dikenakan untuk setiap kegiatan art therapy sebesar Rp. 50.000,- Per orang. Selama ini biaya yang ditentukan untuk setiap kegiatan per pasien dinilai masih terjangkau. Pihak RSKO maupun Pekerja Sosial atau Terapis belum pernah mendapatkan keluhan dari pihak keluarga pasien terkait dengan biaya kegiatan pasien di RSKO. Pernyataan tersebut ditanggapi oleh salah satu pihak keluarga pasien SP, Ibunda pasien "IW" berikut ini: "Kalau menurut saya terjangkau..." (Wawancara Pribadi dengan Ibunda "IW")

d. Ruangan

Kondisi ruangan di Instalasi Rehabilitasi Medik bersih dan cukup cahaya. Hanya saja kondisi ruangan pasien terdapat lorong-lorong yang kurang terkena cahaya. Dalam melaksanakan kegiatan art therapy, Terapis atau Pekerja Sosial memanfaatkan ruang tamu pasien Special Programme (SP) yang dialasi oleh karpet berwarna coklat muda, serta terdapat sofa yang berada disudut ruang tamu. Ruangan berbentuk persegi dengan dilengkapi ventilasi yang banyak sehingga pertukaran udara dan cahaya dapat dikatakan baik. Selain itu, ruang tamu SP luas sehingga dapat menampung jumlah pasien atau peserta yang mengikuti kegiatan art therapy. (Observasi Pribadi, tanggal 14 Mei 2014)

e. Peralatan dan perlengkapan

Peralatan dan perlengkapan yang digunakan memadai, sehingga kegiatan art therapy dapat berlangsung dengan baik. Peralatan dan perlengkapan yang digunakan dalam 
melaksanakan kegiatan art therapy di RSKO masih minim. Dengan menggunakan pulpen, buku gambar, spidol berwarna, pensil, penggaris, pensil warna, dan buku tulis, pasien dapat melakukan kegiatan menggunakan peralatan yang telah disediakan oleh Terapis atau Pekerja Sosial. Semua peserta/pasien mendapatkan peralatan dan ruangan yang digunakan memadai. (Observasi Pribadi, tanggal 14 Mei 2014)

Berdasarkan pembahasan evaluasi input di atas, maka peneliti menilai input dari segi ketersediaan memadai. Dalam kaitannya dengan ketersediaan dinilai relevan dan ketersediaan dalam pelayanan program dinilai baik. Akan tetapi, terdapat beberapa aspek yang perlu dilakukan perbaikan yaitu, RSKO belum memiliki SOP dan modul/kurikulum yang jelas mengenai art therapy. Selain itu, selama ini Pekerja Sosial atau Terapis di RSKO belum pernah mengikuti pelatihan terkait dengan art therapy.

\section{Evaluasi Proses (Process)}

Evaluasi proses terkait dengan kriteria ketersediaan, seperti ketersediaan peralatan, ketersediaan modul, ketersediaan pasien, dan ketersediaan staff atau terapis (SDM). Berikut penjelasan mengenai layanan program art therapy bagi pasien dual diagnosis di RSKO Jakarta:

$>$ Layanan program art therapy

Program art therapy masuk ke dalam pengobatan psikoterapi. Program art therapy dilaksanakan seminggu sekali tepatnya pada hari Rabu pukul 11.30 WIB sampai dengan pukul 12.15 WIB. Berhubung tidak ada ruangan khusus untuk melaksanakan kegiatan art therapy, maka kegiatan tersebut dilaksanakan di ruang tamu SP yang beralaskan karpet berwarna coklat. Sebelum program art therapy dilaksanakan, Pekerja Sosial yang berperan sebagai terapis telah mempersiapkan materi dan metode yang akan digunakan secara matang. Berikut ini, beberapa tahapan yang dilakukan dalam pelaksanaan program art therapy:

a. Memulai kelompok.

b. Membantu anggota agar terlibat.

c. Mengatur iklim yang positif.

d. Klarifikasi tujuan kelompok.

e. Menjelaskan peranan leader atau pemimpin (ketua kelas).

f. Menjelaskan bagaimana terapi akan dijalankan.

g. Membantu anggota menyampaikan harapannya.

h. Mengecek kenyamanan anggota.

i. Menjelaskan aturan terapi.

j. Menjelaskan istilah-istilah khusus yang mungkin akan digunakan.

k. Mencermati interaksi anggota kelompok.

I. Menjawab pertanyaan.

m. Membantu anggota unutk memperhatikan anggota lainnya guna melatih kepedulian dan kepekaan satu sama lainnya, dan

n. Menutup sesi dengan berdo'a bersama. 
Alur pelayanan program art therapy di RSKO dapat dilihat pada bagan di bawah ini:

\section{Gambar 1}

Bagan Alur pelayanan program art therapy

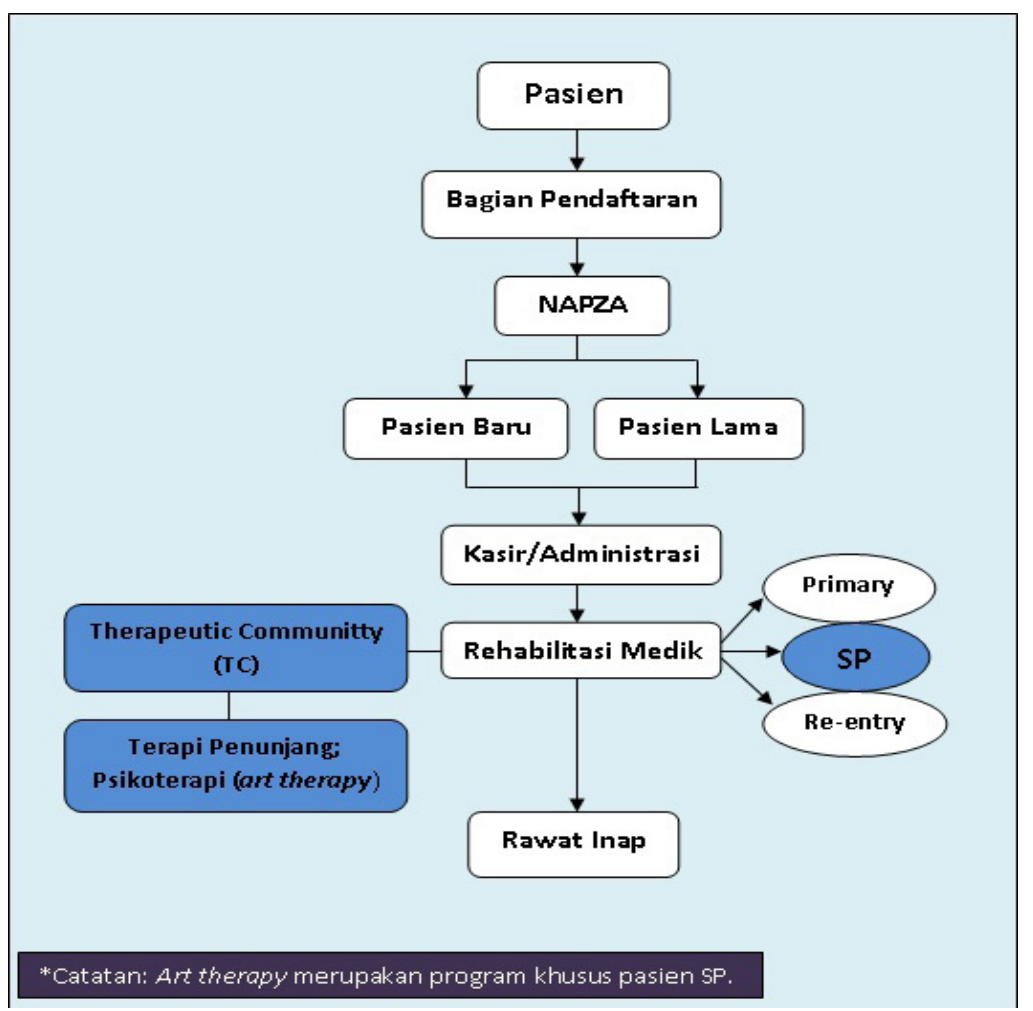

Pada saat kegiatan art therapy berlangsung awalnya pasien terlihat diam, tetapi lama kelamaan pasien/peserta art therapy terlihat antusias dan terlihat ekspresi kegembiraan dari raut wajah mereka. Pekerja Sosial/Terapis terlihat melayani pasien SP dengan sepenuh hati dan sabar dalam menyampaikan materi atau kegiatan yang akan dilaksanakan. Pekerja sosial/Terapis menyampaikan instruksi dengan jelas dan menggunakan bahasa yang ringan sehingga mudah dimengerti oleh para peserta. Selain itu, dengan jumlah pasien/ peserta art therapy yang cukup banyak, Pekerja Sosial/Terapis dapat membagi tugasnya masing-masing sehingga semua peserta mampu ditangani dan diarahkan untuk melaksanakan kegiatan art therapy. Media yang diperuntukan dalam pelaksanaan program art therapy di RSKO masih minim atau terbatas. Pelaksanaan kegiatan art therapy masih menggunakan alat-alat yang sederhana, misalnya spidol bermacam-macam warna, pulpen, pensil, buku tulis, buku gambar, kertas lembar (kertas HVS) dan penggaris. Walaupun dengan persediaan peralatan yang sederhana, semua peserta atau pasien yang mengikuti kegiatan art therapy mendapatkan peralatan yang cukup, tidak satupun dari mereka yang tidak dapat peralatan. Selain itu, ada pula kegiatan yang memanfaatkan barang bekas, seperti botol minuman bekas yakult diisi dengan pasir atau beras yang dapat dibunyikan seperti alat musik.

Fungsi dan peran Pekerja Sosial memberikan terapi alternatif bagi pasien dual diagnosis sekaligus sebagai fasilitator yang berhubungan langsung dengan pasien. Sedangkan fungsi dan peran dari konselor yang bertugas mengamati perilaku dan mengontrol kegiatan pasien rehabilitasi yaitu, memberikan konseling kepada pasien, merencanakan terapi-terapi atau treatment yang sesuai dengan kondisi pasien, dan melakukan rujukan (Studi Dokumen, Buku Standar Pelayanan RSKO). 
Dari pembahasan pelayanan program art therapy di RSKO dikategorikan dengan kriteria ketersediaan pelayanan dan kemampuan layanan program. Dapat disimpulkan bahwa pelayanan program art therapy di RSKO relevan dan ketersediaan dalam proses pelayanan program, serta pelayanan yang diberikan Pekerja Sosial dinilai baik. Walaupun dari segi peralatan masih minim dan perlu tambahan peralatan untuk kegiatan art therapy.

\section{Evaluasi Hasil (Outcomes)}

Dalam evaluasi hasil (outcomes), penilaian mengarah kepada efektifitas dan dampak (overall impact) dari program art therapy bagi pasien dual diagnosis di RSKO Jakarta. Berdasarkan data yang diperoleh sebagai berikut:

1. Efektifitas

Efektifitas menggambarkan tingkat pencapaian target program art therapy dengan membandingkan antara hasil (output) dengan asupan (input) yang digunakan (waktu, SDM, alat, dan sebagainya). Dalam memberikan layanan program art therapy, RSKO tidak menetapkan jumlah pasien sebagai penerima manfaat program. Sasaran program art therapy di Rumah Sakit Ketergantungan Obat Jakarta adalah pasien yang sedang mengikuti program rehabilitasi dan berada dalam fase Special Program (SP). Akan tetapi dilihat dari kondisi atau keadaan si pasien itu sendiri. Misalkan, salah satu pasien kondisinya sedang parah maka pasien tersebut tidak dapat mengikuti kegiatan art therapy. Jadi pasien SP yang dapat mengkuti art therapy yakni, pasien yang secara psikisnya siap menerima materi dan dapat berkomunikasi dengan baik.

Pada periode 20011-2014 jumlah pasien Special Programme (dual diagnosis) adalah:

Tabel 5

Jumlah Pasien Special Programme Tahun 2011-2014

\begin{tabular}{|c|c|}
\hline Tahun & Jumlah Pasien \\
\hline 2011 & 9 orang \\
\hline 2012 & 17 orang \\
\hline 2013 & 14 orang \\
\hline 2014 & 15 orang \\
\hline
\end{tabular}

Pada tahun 2014 data anggota atau pasien dual diagnosis (SP) di RSKO Jakarta masih dapat berubah. Menurut Pekerja Sosial RSKO sebagai pelaksana program art therapy menilai bahwa program art therapy yang diberikan kepada pasien dual diagnosis di RSKO dapat dikatakan efektif. Seperti yang dipaparkan oleh Bapak Agus Darmawan selaku Pekerja Sosial RSKO berikut ini:

"Kalau menurut saya program art therapy yang dilaksanakan di RSKO dapat dikatakan efektif karena para pasien ketika berlangsungnya kegiatan art therapy terlihat antusias dan senang. Memang tidak semua tujuan dari art therapy bisa dicapai, tetapi paling enggak mereka udah mau melakukan aktivitas yang sudah ada untuk melatih cara berpikir mereka, melatih motorik mereka, mencurahkan perasaan mereka melalui seni, menambah motivasi, dan juga menyenangkan perasaan mereka."

2. Dampak

Dampak (impact) menggambarkan perubahan yang diperoleh dalam jangka panjang. Dampak yaitu pengaruh program art therapy baik preventif maupun kuratif terhadap pasien dual 
diagnosis. Dalam hal ini dampak memberikan efek yang dapat dirasakan secara langsung dan secara tidak langsung dalam jangka waktu yang panjang. Baik positif maupun negatif, yang dihasilkan sebuah program, langsung atau tidak langsung, dikehendaki maupun tidak dikehendaki. Berikut ini pembahasan mengenai dampak pelaksanaan program art therapy:

Efek yang dirasakan secara langsung oleh pasien dual diagnosis dalam pelaksanaan program art therapy di RSKO adalah membuat pasien menjadi relaks, menghibur diri pasien/membuat pasien menjadi senang, membawa pasien ke arah pikiran yang positif, memotivasi diri pasien, dan menghilangkan kejenuhan. Seperti yang diungkapkan oleh klien "IW”: “...feeling saya jadi senang, membantu saya jadi lebih bijak, membuat diri saya menjadi lebih baik, dapat merelaks sejenak pikiran, dan jadi semangat lagi." (Wawancara Pribadi dengan Klien "IW", tanggal 30 April 2014). Klien " $T$ ” juga mengungkapkan: “...mendapatkan pengalaman baru, stress saya hilang, terus jadi membuat perasaan saya senang." (Wawancara Pribadi dengan Klien "T", tanggal 29 April 2014). Pernyataan serupa juga diungkapkan oleh klien "AHG”: “...menghilangkan kejenuhan kita, membuat perasaan kita jadi senang, bisa juga jadi terapi otak kiri dan otak kanan kita..." (Wawancara Pribadi dengan Klien “AHG”, tanggal 12 Mei 2014).

Kemudian efek yang secara tidak langsung dirasakan oleh pasien dual diagnosis dalam pelaksanaan program art therapy di RSKO adalah pasien dapat berfungsi sosial kembali sesuai dengan peran sosialnya. Dampak program art therapy terhadap pasien dual diagnosis meliputi: dampak fisik, dampak psikis, dan dampak sosial. Berikut penjelasan mengenai dampak fisik,dampak psikis, dan dampak sosial yang dirasakan oleh pasien dual diagnosis:

a. Dampak Fisik

Dampak program art therapy bagi pasien dual diagnosis secara fisik dapat meringankan rasa sakit pasien dan memperbaiki sel-sel otak pasien. Seperti yang dipaparkan oleh Pekerja Sosial RSKO, Bapak Agus Darmawan berikut ini:

"Pasien dianjurkan untuk minum obat secara teratur, secara medis kondisi fisiknya membaik, tapi kalau melihat perubahan fisik dari art therapy belum terlihat secara pesat. Paling bisa meredakan sakit pasien, jadi karena perasaannya senang berpengaruh kepada keadaan fisiknya mereka. Selain itu dapat memperbaiki sel-sel otak pasien."

Salah satu keluarga pasien yaitu Ibu klien "IW" juga mengungkapkan: "Secara fisik, saya melihat "IW" lebih sehat. Saya tanya juga dia bilang sudah bisa tidur."

b. Dampak Psikis

Selama pasien dual diagnosis mengikuti kegiatan art therapy di RSKO, terlihat perubahan pada psikisnya antara lain: pasien terlihat lebih percaya diri, dapat berkomunikasi dengan baik, pasien terlihat lebih tenang, dan semangat mengikuti kegiatan yang ada. Seperti yang dipaparkan oleh Pekerja Sosial RSKO, Bapak Agus Darmawan:

"Ya.. secara psikis pasien sudah terlihat perubahan yang cukup signifikan. Pasien terlihat senang, antusias, mau bergerak melakukan kegiatan, dan sudah mulai bisa diajak berkomunikasi, serta mengikuti instruksi yang diberikan pada saat kegiatan art therapy berlangsung."

Pernyataan serupa juga dipaparkan oleh salah satu keluarga pasien, Ibu klien "IW: "Kalau perubahan psikis terlihat sekali jauh berbeda dengan yang sebelumnya. "IW" terlihat lebih tenang, mau diajak ngobrol, komunikasinya dia juga baik.” 
c. Dampak Sosial

Setelah pasien menjalani pemulihan dengan mengikuti kegiatan atau terapi yang sudah dijadwalkan termasuk art therapy, terlihat perubahan sosial pada diri pasien diantaranya: pasien dapat diajak berkomunikasi dengan baik, pasien dapat bergaul dengan teman-temannya dan dengan konselor ataupun petugas di RSKO. Seperti yang dipaparkan oleh Pekerja Sosial RSKO, Bapak Agus Darmawan:

“...Pasien bisa menyesuaikan diri atau beradaptasi dengan lingkungan sekitarnya dan dengan teman-temannya. Mereka mau berkomunikasi antara satu sama lainnya karena pada dasarnya mereka itu malas bersosialisasi dan cenderung menutup diri atau menyendiri."

Pernyataan serupa juga ditanggapi oleh salah satu keluarga pasien, Ibu klien "IW": "Perubahan sosial yang terlihat "IW" sudah tidak terlihat menyendiri, mulai terbuka dengan perasaannya, saya lihat dia juga bergaul dengan teman-temannya di RSKO.”

Dari data diatas dapat saya simpulkan bahwa keberadaan program art therapy berpengaruh bagi pemulihan pasien dual diagnosis. Hasil evaluasi ini dinilai efektif karena dapat merubah kondisi pasien ke arah yang lebih baik terutama aspek psikis yang lebih tenang dan aspek sosial pasien dalam berinteraksi dengan Pekerja Sosial/Terapis, Konselor, keluarga, maupun teman-temannya. Sehingga dari dampak fisik, dampak psikis, dan dampak sosial yang pasien alami dapat merubah pasien menjadi berfungsi sosial kembali sesuai dengan peran sosialnya masing-masing.

\section{Penutup}

\section{Kesimpulan}

Berdasarkan hasil penelitian yang telah penulis lakukan maka dapat disimpulkan bahwa program art therapy merupakan program terapi penunjang bagi pasien dual diagnosis di Rumah Sakit Ketergantungan Obat (RSKO) Jakarta yang ditujukan secara khusus bagi pasien dual diagnosis yang menjalani rehabilitasi, tepatnya berada pada fase Special Program (SP). Program art therapy berfungsi untuk menghibur diri pasien, mengetahui konflik-konflik yang tidak disadari oleh pasien, membantu pasien untuk mengungkapkan masalahnya, meningkatkan kognitif pasien, mengasah motorik pasien, meningkatkan rasa percaya diri pasien, memberikan simulasi peran pasien, memahami emosi, dan meningkatkan kreatifitas pasien.

Hasil evaluasi program art therapy bagi pasien dual diagnosis di RSKO Jakarta dengan kriteria ketersediaan dinilai relevan, serta ketersediaan dalam pelayanan program dinilai baik. Proses pelayanan program art therapy dinilai relevan dan ketersediaan proses pelayanan program, serta pelayanan yang diberikan Pekerja Sosial dinilai baik. Walaupun ketersediaan SOP dan kurikulum mengenai art therapy di RSKO belum ada. Dari segi efektifitas, program art therapy bagi pasien dual diagnosis dinilai efektif karena dapat merubah kondisi pasien ke arah yang lebih baik terutama aspek psikis yang lebih tenang dan aspek sosial pasien dalam berinteraksi dengan Pekerja Sosial, Konselor, keluarga, dan teman-temannya.

Temuan dalam penelitian ini menunjukkan bahwa pada kasus dual diagnosis (NAPZA-Skizofrenia), program art therapy sangat membantu pemulihan pasien dual diagnosis dalam menjalani rehabilitasi Therapeutic Community (TC) berbasis Rumah Sakit. 


\section{Saran}

a. Untuk Rumah Sakit Ketergantungan Obat (RSKO) Jakarta

1. Memperbaiki kurikulum art therapy yang digunakan untuk pemulihan pasien dual diagnosis.

2. RSKO mengadakan pelatihan bagi Pekerja Sosial atau Terapis terkait dengan art therapy.

3. Membuat modul khusus program art therapy agar pelaksanaan kegiatannya menjadi lebih baik dari sebelumnya.

4. RSKO menyediakan ruangan khusus untuk kegiatan art therapy agar fokus pasien tidak terbagi, sehingga tidak menggunakan ruang tamu Special Program (SP).

5. Menambah peralatan yang akan digunakan untuk melaksanakan kegiatan art therapy.

b. Untuk Pasien Dual Diagnosis di RSKO Jakarta

1. Melanjutkan program art therapy sebagai terapi penunjang bagi pemulihan diri.

2. Saling menguatkan atau memberikan motivasi kepada sesama pasien. 


\section{Bibliografi}

\section{Buku}

Adi, Isbandi Rukminto. Pemberdayaan, Pengembangan Masyarakat dan Intervensi Komunitas Pengantar pada Pemikiran dan Pendekatan Praktis. Jakarta: FEUI Press, 2003.

Arikunto, Suharsimi. Penilaian Program Pendidikan. Yogyakarta: Bina Aksara, 1998.

Brooker, Christine Kamus Saku Keperawatan. Jakarta: EGC, 2001.

Case, Caroline and Dalley, Tessa. The Handbook of Art Therapy. London and New York: Rouledge, 1992.

Chaplin, J.P. Kamus Lengkap Psikologi. Jakarta: PT. Raja Grafindo Persada, 2006.

Djohan, Bahder. Hubungan Antara Dokter, Perawat dan Pasien dalam Pembangunan Mental Bangsa Kita. Jakarta: PT. Sinar Hudaya, 1972.

Ghony, M. Djunaidi dan Almanshur, Fauzan. Metodologi Penelitian Kualitatif. Jogjakarta: Ar-Ruzz Media, 2012.

Gulo, W. Metodologi Penelitian. Jakarta: PT. Grasindo, 2002.

Hadari, Nawawi. Instrumen Penelitian Bidang Sosial. Yogyakarta: Gajah Mada Universitiy, 1992.

Hawari, Dadang. Al-Qur'an: Ilmu Kedokteran Jiwa dan Kesehatan Jiwa. Yogyakarta: PT. Dana Bhakti Prima yasa, 2004.

Pelatihan Relawan Bimbingan Rohani Pasien (Jakarta: Dompet Dhuafa Republika, 2003.

Penyalahgunaan dan Ketergantungan NAZA (Narkotik, Alkohol, dan Zat Adiktif. Jakarta: Balai Penerbit FKUI 2006.

Irawan, Prasetya. Penelitian Kualitatif dan Kuantitatif Untuk Ilmu-Ilmu Sosial.Depok: FISIP UI, 2006.

J, Benjamin dan Sadock, Virginia A. Buku Ajar Psikiatri Klinis. Jakarta: Penerbit Buku Kedokteran/ EGC, 2010.

Johnston, Mary. Relasi Dinamis antara Pekerja Sosial dengan Klien dalam Setting Rumah Sakit. Surakarta: Tim RM Rumah Sakit Orthopedi dan Prothese Prof.DR.R.Soeharso, 1988.

Mallo, Monasse. Metode Penelitian Sosial. Jakarta: Penerbit Karunika, 1998.

Maslim, Rusdi. Buku Saku Diagnosis Gangguan Jiwa; Rujukan Ringkas dari PPDGJ-III. Jakarta: Departemen, t.t.

Mintarti, Nana dkk. Zakat \& Empowering, Kajian Perumusan Performance Indicator bagi Program Pemberdayaan Masyarakat Berbasis Zakat. Jurnal Pemikiran dan Gagasan, vol. 2, Juni 2009.

Moleong, Lexy J. Metode Penelitian Kualitatif. Bandung: PT. Remaja Rosdakarya, 1993. Metodologi Penelitian Kualitatif. Bandung: PT. Remaja Rosdakarya. 2004. Metode Penelitian Kualitatif. Bandung: PT. Remaja Rosdakarya, 2009.

Naunghelarta, Yanti. Buku Seri Penyakit Saraf dan Kejiwaan. Jakarta: LARAS ADV, 2012.

Partanto, Pius A dan Al Barry, M Dahlan. Kamus Ilmiah Popoler. Surabaya: Arloka, 1994.

Partodiharjo, Subagyo Kenali Narkoba dan Musuhi Penyalahgunaannya. T. Tp.: LKP Yayasan Karya Bhakti, 2004. 
Prayitno. Dasar-dasar Bimbingan dan Konseling. Jakarta: PT. Rincka Cipta, 2004.

Rubin, Judith Aron. Child Art Therapy. New York: Van Nostrand Reinhold Company Inc, 1984.

Sugiyono. Memahami Penelitian Kualitatif. Bandung: Alfabeta, 2010.

Metode Penelitian Pendidikan Pendekatan Kuantitatif, Kualitatif, dan R\&D. Bandung: CV Alfabeta, 2010.

Suharto, Edi. Membangun Masyarakat Memberdayakan Masyarakat, Kajian Strategis Pembangunan Kesejahteraan Sosial dan Pekerjaan Sosial. Bandung: PT. Refika Aditama, 2005. Sugiyono. Metode Penelitian Pendidikan Pendekatan Kuantitatif, Kualitatif, dan R\&D. Bandung: CV Alfabeta, 2010.

Soeharto, Irawan. Metode Penelitian Sosial: Suatu Teknik Penelitian Bidang Kesejahteraan Sosial dan Ilmu Sosial Lainnya. Bandung: PT. Remaja Rosdakarya 2004.

Solichin, Jusni Ichsan, dkk. Buku Pedoman Kesehatan Jiwa. Jakarta: Departemen Kesehatan, 2003.

Suhardja, Gai. Drawing as Art therapy (In Progress. FSRD UK Maranantha Peneliti Kajian Ilmiah, 2003.

Tayibnapis, Farida Yusuf. Evaluasi Program dan Instrumen Evaluasi untuk Program pendidikan dan Penelitian. Jakarta: Rineka Cipta, 2008.

Thaha, Idris, ed. Pedoman Penulisan Skripsi, Tesis, dan Disertasi UIN. Jakarta, UIN Jakarta Press: 2007.

Uditomo, Purwa dkk. Zakat \& Empowering, Evaluasi dan Kaji Dampak Program Layanan Kesehatan Cuma-Cuma. Jurnal Pemikiran dan Gagasan, vol. 2, Juni 2009.

Usman, Husaini dan Akbar, Purnomo Setiady. Metodologi Penelitian Sosial. Jakarta: PT. Bumi Aksara, 2009.

Warjowarsito, S. dan W, Tito. Kamus Lengkap Bahasa Inggris-Indonesia, Indonesia-Inggris. Bandung: T.p.n.,1980.

Weller, Barbara F. Kamus Saku Keperawatan. Jakarta: EGC, 2005.

Wiramihardja, Sutardjo A. Pengantar Psikologi Klinis. Bandung: PT. Refika Aditama 2007.

\section{Buletin}

Elly Hotnida Gultom. "Buletin Ilmiah Populer RSKO Tantangan Penanganan Masalah Adiksi NAPZA (Peran Perawat dalam Program Terapi dan Pemberdayaan Pasien dengan Dual Diagnosis". Jakarta: Instalasi Penelitian dan Pengembangan RSKO.

Fauzy Masjhur, "Buletin Ilmiah Populer RSKO Jakarta: Peran Rumah Sakit Ketergantungan Obat

Dalam Penanganan Masalah NAPZA di Indonesia". Jakarta: Instalasi Penelitian dan Pengembangan RSKO, 2008.

\section{Jurnal}

Fakultas Psikologi Universitas Surabaya. Art Therapy. No. 39 vol. 10 April-Juni. Surabaya: Anima 1995.

\section{Kamus}

Departemen Pendidikan Nasional. Kamus Besar Bahasa Indonesia. Jakarta: Balai Pustaka, 2001.

Departemen Pendidikan dan Kebudayaan. Kamus Besar Bahasa Indonesia. Jakarta: Balai Pustaka, 1988. 
Tim Penyusun Kamus Pusat Pembinaan dan Pengembangan Bahasa, Kamus Besar Bahasa Indonesia. Jakarta: Balai Pustaka, 1998.

\section{Internet}

Adam. "Arti Definisi/Pengertian Zat Adiktif." Artikel diakses pada 23 Februari 2014 dari http:// www.organisasi.org/2014/0223/arti-def.html

Al. Qur'an Online. "Surah Al-Maidah (Ayat 90 dan 91)". Artikel diakses pada 3 Januari 2014 dari http://m.alquranonline.web.id/alquran.php

American Art Therapy Association (AATA). "The History of Art Therapy.” Artikel diakses pada 10 Mei 2014 dari http://www.Arttherapyjournal.org/2014/0510/index.html

Collingwood, Jane. "Art Therapy: Beneficial Schizophrenia Treatment?" Artikel diakses pada 10 Mei 2014 dari http://psychcentral.com/lib/art-therapy-beneficial-schizophreniatreatment/00015622

Dedi. "Dampak Langsung dan Tidak Langsung Penyalahgunaan Narkoba." Artikel diakses pada 3 Januari 2014 dari http://dedihumas.bnn.go.id/read/section/artikel/dampak-langsung-dantidak-langsung-penyalahgunaan-narkoba

Fajrin, Yan. "Skizofrenia Diagnosis." Artikel diakses pada 23 Februari 2014 dari http://www.newsmedical.net/health/Schizophrenia-Diagnosis-\%28Indonesian\%29.aspx

Fitranta, Johny Bayu. "Klasifikasi Gangguan Jiwa." Artikel diakses pada 3 januari 2014 dari http:// www.medicinesia.com/kedokteran-klinis/neurosains-kedokteran-klinis/klasifikasigangguan-jiwa/

Kardenti, Denti. "Metode-Metode Pekerjaan Sosial," Artikel diakses pada 27 Agustus 2014 dari http://scribd.com/Metode-metode/PekerjaanSosial/2014/0827-html

Kelompok Perawat. "Asuhan Keperawatan Klien dengan Sindrom Putus Zat (NAPZA)." Artikel diakses pada 3 Januari 2014 dari http://madiun-gleekapay.blogspot.com/2014/0103/index. html

Lestari, Iis “Narkoba dan NAPZA serta Psikotropika.” Artikel diakses pada 3 Januari 2014 dari http:// www.kamuslife.com/index.html

Morgan, Lee. "Art Therapy." Artikel diakses pada 10 Mei 2014 dari http://www.healthline. com/2014/0510/html

Nawazir. "Pengertian Terapi." Artikel diakses pada 8 Mei 2014 dari http://www.id.shvoong.com/ pengertian-terapi/2014/0508/html.

Noegraha, Agoes. "Mengenal Penggolongan Narkotika, Psikotropika, dan Zat Adiktif Lainnya." Artikel diakses pada 23 Februari 2014 dari http://web.unair.ac.id/artikel_Napza-Mengenal/ Penggolongan/Narkotika/PsikotropikadanZatAdiktifLainnya.html

Priya. "Definisi NAPZA.” Artikel diakses pada 23 Februari 2014 dari https://www.k4health.org/sites/ default/files/NAPZA/LENGKAP/

Purwanto. S, Admin Setiyo. "Mengenali dan Mengembangkan Kreativitas Peserta Didik." Artikel diakses pada 23 Februari 2014 dari www.elearn.bpplsp-reg5.go.id/2014/0223.html

Raharjo, Santoso Tri. "Pendekatan Sistem dalam Praktik Pekerjaan Sosial," artikel diakses pada 27 Agustus 2014 dari http://kesos.unpad.ac.id/2014/0827/p=578.html

Rakyat Media. “Kepala BNN:Tahun 2014-2015 Pengguna Narkoba Meningkat.” Artikel diakses 
pada 3 Januari 2014 dari http://rakyatmedia.com/2014/0103.html

Sandra, Arsepta Kurnia. “Art Therapy.” Artikel diakses pada 3 Januari 2014 dari http://www. goodtherapy.org/art-therapy.html

Servasius. "Dual Diagnosis Treatment." Artikel diakses pada 23 Februari 2014 dari http://www. dualdiagnosis.org/you-should-know-about-treatment/

Syaifudin, Achmad. "Mengenal Dampak Narkoba." Artikel diakses pada 23 Februari 2014 dari http:// www.Makassarkota.go.id/2014/0223/index.html.

Tuasikal, Muhammad Abduh. "Narkoba Dalam Pandangan Islam.” Artikel diakses pada 3 Januari 2014 dari http://muslim.or.id/fiqh-dan-muamalah/narkoba-dalam-pandangan-islam.html

Universitas Sumatera Utara (USU). "Asuhan Keperawatan Klien dengan Masalah Psikososial dan Gangguan Jiwa," artikel diakses pada 3 Januari 2014 dari http://usupress.usu.ac.id/ AsuhanKeperawatanKliendenganMasalahPsikososialdanGangguanJiwa/

\section{Dokumentasi}

Studi Dokumen. Buletin RSKO Tahun 2008.

Studi Dokumen. Brosur Profil RSKO.

Studi Dokumen. Instalasi Rekam Medik. Total Data Rekap Pasien RSKO Jakarta.

Studi Dokumen, Buku Rekam Medik Pasien RSKO. Klien "AHG”.

Studi Dokumen. Buku Rekam Medik Pasien RSKO,.Klien "IW".

Studi Dokumen. Buku Rekam Medik Pasien RSKO, klien "T".

Studi Dokumen Buku Standar Pelayanan Rumah Sakit Ketergantungan Obat Jakarta.

Studi Dokumen. Walking Paper Residen Instalasi Rehabilitasi. 